\title{
Tacrolimus-Based Immunosuppression in Pediatric Renal Transplantation
}

\author{
M.L. Jordan, R. Shapiro, V. Scantlebury, C. Vivas, D. Ellis, S. Lombardozzi-Lane, and T.E. \\ Starzl \\ Division of Urologic Surgery/Transplantation and Starzl Transplantation Institute, University of \\ Pittsburgh Medical Center, Pittsburgh, Pennsylvania, USA.
}

Tacrolimus has been shown to be a safe and effective immunosuppressive agent in adult renal transplantation with significant advantages, including the ability to taper corticosteroids in up to $65 \%$ of recipients. ${ }^{1-4}$ The use of this agent in the pediatric population is less well described. We and others have previously reported that its use in pediatric patients is associated with excellent patient and graft survival results in a relatively small number of patients. ${ }^{5-9}$ Here we report our expanded experience on the use of tacrolimus in pediatric renal transplantation.

\section{PATIENTS AND METHODS}

Between December 1989 and December 1996, 82 pediatric renal transplants were performed using tacrolimus-based immunosuppression without antilymphocyte antibody induction therapy. The mean age of the recipients was $10.6 \pm 5.2$ years (range 0.7 to 17.9 years). More than one-quarter of patients could be categorized as 'high-risk' with 18 (22\%) cases being retransplantations and $6(7 \%)$ patients having panel reactive antibody (PRA) levels $\geq 40 \%$. A total of $34(41 \%)$ cases were with living donors and $48(59 \%)$ were with cadaveric donors, with a mean donor age of $27.3 \pm 14.6$ years (range 0.7 to 50 years), and a mean cold ischemia time in the cadaveric cases of $26.5 \pm 8.8$ hours. The mean number of HLA matches and mismatches was $2.8 \pm 1.2$ and $2.9 \pm 1.3$. respectively, and there were five $(6 \%) \mathrm{O}$-antigen mismatches. The mean duration of follow-up was $4.0 \pm 0.2$ years (range 0.6 to 7.5 years). Immunosuppression consisted of a $0.15 \mathrm{mg} / \mathrm{kg}$ oral dose of tacrolimus preoperatively, with postoperative administration at 0.05 to $0.10 \mathrm{mg} / \mathrm{kg}$ as a continuous intravenous infusion. Patients were subsequently converted to oral administration of tacrolimus at a dose of $0.15 \mathrm{mg} /$ $\mathrm{kg}$ twice daily. The dose of tacrolimus was adjusted according to target whole blood trough levels. The levels aimed for were 20 to $25 \mathrm{ng} / \mathrm{mL}$ during the first 2 weeks, 15 to $20 \mathrm{ng} / \mathrm{mL}$ at 1 month, 10 to $15 \mathrm{ng} / \mathrm{mL}$ at 3 months, and $<5$ to 8 to $9 \mathrm{ng} / \mathrm{mL}$ over the long term. Patients also received tapered corticosteroid therapy, the aim being to withdraw corticosteroids completely by month 6 .

\section{RESULTS}

One- and 4-year actuarial patient survival was $99 \%$ and $94 \%$, and actuarial graft survival was $98 \%$ and $84 \%$, respectively (Table 1 ). There was no significant difference in patient and graft survival between the living donor and cadaveric donor recipients. However, 4-year graft survival was significantly higher in patients receiving a primary transplant compared with retransplant patients $(P<.02)$. PRA levels were also a prognostic indicator of graft survival, with $87 \%$ 4-year survival in those with levels $<40 \%$ and $57 \%$ in patients with levels $\geq 40 \%$

(C) 1999 by Elsevier Science Inc.

Address reprint requests to M.L. Jordan, MD, Department of Surgery, University of Pittsburgh Medical Center, Pittsburgh, PA 15213. 
$(P<.03)$. Causes of graft loss included rejection $(n=5)$, disease recurrence $(n=5)$, pancreatitis $(n=2)$, infection $(n=1)$, and noncompliance $(n=1)$.

The mean serum creatinine level was $1.1 \pm 0.5 \mathrm{mg} / \mathrm{dL}$, and the corresponding calculated creatinine clearance was $88 \pm 25 \mathrm{~mL} / \mathrm{min}$ per $1.73 \mathrm{~m}^{2}$. Overall, prednisone was withdrawn in $66 \%$ of successfully transplanted patients at the 4 -year follow-up time point. The mean dose of tacrolimus at this time was $0.18 \pm 0.12 \mathrm{mg} / \mathrm{kg} / \mathrm{d}$, with mean levels of $9.9 \pm 4.6 \mathrm{ng} / \mathrm{mL}$. The overall dose of corticosteroids was $0.04 \pm 0.09 \mathrm{mg} / \mathrm{kg} / \mathrm{d}$, while the mean dose in patients remaining on corticosteroids was $0.17 \pm 0.11 \mathrm{mg} / \mathrm{kg} / \mathrm{d}$. In the corticosteroid-free children, the mean standard deviation height scores ( $\mathrm{Z}$ score) at the time of transplantation, and at 1 and 4 years, were $-2.3 \pm 2.0,-1.7 \pm 1.0$, and $+0.36 \pm 1.5$, respectively, showing an improvement over time with corticosteroid dose reduction and subsequent withdrawal. In those remaining on corticosteroids, the mean $\mathrm{Z}$ scores at 1 and 4 years were $-2.0 \pm 1.1$ and $-0.6 \pm 2.9$, respectively. Furthermore, $86 \%$ of the successfully transplanted patients were not taking any antihypertensive medications. Mean cholesterol levels were also within the acceptable range, at $155 \pm 31 \mathrm{mg} / \mathrm{dL}$.

\section{Incidence of Rejection}

Although the overall incidence of acute rejection was $44 \%$, there was a clear reduction in rejection episodes over time as greater experience was gained in the use of tacrolimus. Between December 1989 and December 1993, the incidence of acute rejection was 63\%, but was significantly reduced to 23\% $(P=.0003)$ between January 1994 and December 1996 . The incidence of both corticosteroid-resistant rejection and delayed graft function was 5\%. A total of $2 \%$ of patients with delayed graft function required dialysis within 1 week of transplantation.

\section{Infection}

The overall incidence of cytomegalovirus infection (CMV) was 13\%. Again, a decreased incidence of CMV was observed over time, with $17 \%$ of patients being affected between December 1989 and December 1992, which was reduced to 12\% during the subsequent 4 years.

\section{DISCUSSION}

There has been relatively little experience with the use of tacrolimus in pediatric renal transplantation including reports from our own institution ${ }^{5-8} 810$ as well as the University of Minnesota1 1 and Johns Hopkins Hospital ${ }^{9}$ describing excellent patient and graft survival results in the short term. We currently report patient and graft survival results of $99 \%$ and $94 \%$ after 1 year and $98 \%$ and $84 \%$ after 4 years, with excellent renal function and the ability to taper corticosteroids in the majority of children. One concern with the use of tacrolimus in children has been the relatively high incidence of Epstein-Barr virus (EBV)-related posttransplant lymphoproliferative disorder (PTLD) which in the early part of this series was 17\% (December 1989 to December 1992, 5 cases in 29 patients). However, in the latter part of this series (January 1993 to December 1996) the incidence had decreased to 4\% (2 cases in 53 patients). All of these cases responded to temporary discontinuation of immunosuppression and intravenous ganciclovir and there were no deaths or short-term graft losses. One patient lost the allograft because of chronic rejection 3 years after being treated for PTLD. This indicates that there is a learning curve associated with the use of tacrolimus in the pediatric population. In EBV mismatched recipients we are currently following serial EBV polymerase chain reaction (PCR) levels to allow early identification and the use of ganciclovir treatment in seroconverting children. In addition, we have become more judicious in the early reduction of tacrolimus levels in the postoperative period in this group of patients. We feel that these factors have led to the observed reduction in the incidence of PTLD in the latter part of our series. The early incidence of insulin-dependent posttransplant diabetes mellitus (PTDM) was 
$9 \%$ in successfully transplanted patients, but with reduction of tacrolimus doses and corticosteroid tapering the final incidence was only $1 \%$. The significant benefits in this series have been the gratifying improvements in growth as reflected by improved mean standard deviation height scores in children who were able to be weaned off corticosteroids.

\section{CONCLUSION}

These data demonstrate the efficacy of tacrolimus-based immunosuppression in pediatric renal transplant recipients, with reasonable patient and graft survival, routine achievement of corticosteroid and antihypertensive medication withdrawal, and gratifying increases in growth.

\section{REFERENCES}

1. Shapiro R, Jordan ML, Scantlebury V, et al. Transplantation 1995;59:485. [PubMed: 7533343]

2. Starzl TE, Fung J, Jordan ML, et al. JAMA 1990;264:63. [PubMed: 1693970]

3. Pirsch JD, Miller J, Deierhoi MH, et al. Transplantation 1997;63:977. [PubMed: 9112351]

4. Mayer AD, Dmitrewski J, Squifflet J, et al. Transplantation 1997;64:436. [PubMed: 9275110]

5. Schneck FX, Jordan ML, Jensen CWB, et al. J Urol 1992;147:1585. [PubMed: 1375663]

6. Ellis D, Shapiro R, Jordan ML, et al. Pediatr Nephrol 1994;8:193. [PubMed: 7517171]

7. Shapiro R, Scantlebury V, Jordan ML, et al. Pediatr Nephrol 1995;9:543. [PubMed: 8580004]

8. Shapiro R, Scantlebury V, Jordan ML, et al. Transplantation 1996;62:1752. [PubMed: 8990356]

9. McKee M, Segev D, Wise B, et al. J Pediatr Surg 1997;32:688. [PubMed: 9165452]

10. Shapiro R, Scantlebury V, Jordan ML, et al. Transplantation 1999;67:299. [PubMed: 10075598]

11. Birk PE, Cook MD, Schmidt WJ, et al. Transplant Proc 1996;28:993. [PubMed: 8623493]

Transplant Proc. Author manuscript; available in PMC 2010 November 9. 


\section{Table 1}

One- and 4-Year Patient and Graft Survival Rates in Tacrolimus-Treated Pediatric Renal Transplant Recipients

\begin{tabular}{lcc}
\hline & 1 Year & 4 Years \\
\hline Actuarial patient survival $(\%)$ & 99 & 94 \\
Actuarial graft survival $(\%)$ & 98 & 84 \\
Living donor $(n=34)$ & 100 & 96 \\
Cadaver donor $(n=48)$ & 86 & 81 \\
First transplant $(n=64)$ & 100 & $90^{*}$ \\
Retransplant $(n=18)$ & 89 & 66 \\
PRA $<40 \%(n=76)$ & 99 & $87^{\dagger}$ \\
PRA $\geq 40 \%(n=6)$ & 86 & 57 \\
\hline
\end{tabular}

${ }^{*} P<.02$ versus retransplant group. $P<.03$ versus PRA $\geq 40 \%$ group. 